\title{
BEHAVIOUR OF FIBRE REINFORCE CONCRETE BEAM IN PURE TORSION
}

\author{
C.Arvind Kumar ${ }^{1}$, Madan Mohan², D.V.S.P Rajesh ${ }^{3}$, Prathik Kulkarni ${ }^{4}$ \\ ${ }^{1}$ Assistant Professor, Civil Engineering, Guru Nanak Institution \& Technical Campus, Telengana, India \\ ${ }^{2}$ Professor, Civil Engineering, Guru Nanak Institute Technology, Telengana, India \\ ${ }^{3}$ Assistant Professor, Civil Engineering, Guru Nanak Institution \& Technical Campus, Telengana, India \\ ${ }^{4}$ Assistant Professor, Civil Engineering, Guru Nanak Institution \& Technical Campus, Telengana, India
}

\begin{abstract}
It has been observed that a plain concrete member when subjected to cracking torque fails along a spiral inclined at $45^{0}$ to the axis of the member. It is obvious that reinforcement in the form of $45^{\circ}$ rectangular spirals will be most effective in resisting torque in case of a member of rectangular section. Provision of only longitudinal bars without stirrups increases torsional strength to the extent of $15 \%$, the most appropriate system of torsional reinforcement consists of longitudinal bars together with closed transverse stirrups. In view of above observations, an attempt is made to study the following aspects: Behaviour of reinforced concrete beam under. 1)Pure torsional, (a)Without glass fibres (b)With glass fibres 2)The effect of increase of fibre percentage on torsional resistance of beam. 3) To develop torque. Vs. twist relation of the beams.
\end{abstract}

The experimental program consists of casting 4 reinforced concrete beams of size $150 \mathrm{~mm}$ X150 mm and length $2 \mathrm{~m}$. Two of them were cast without fibres to make a comparative study with the remaining 3 beams; one beam is cast with $0.5 \%$ fibre by weight, one beam 1.0\% fibre by weight in the rest one beam $1.5 \%$ fibre by weight added. The longitudinal reinforcement, spacing of shear stirrups is kept constant.

Keywords: Aspect ratio, Glass Fibres, Reinforced concrete, Beam,Torsional strength

\section{INTRODUCTION}

Twisting moments, which are essential to maintain equilibrium of the structure, give rise to equilibrium torsion. Equilibrium torsion assumes much greater importance in the concrete structure. Twisting moments which are not essential for equilibrium but are present only to establish compatibility of deformation give rise to compatibility torsion while the neglect of compatibility torsion may lead to undesirable cracking and inadequate serviceability, the neglect of equilibrium torsion may lead to disastrous collapse of the structure[4]

Depending upon the nature of applied loading, structural form and position of the member under consideration in the structural system, the twisting moments may be static of dynamic, transient of sustained and non-repetitive or cyclic. Static torsion occurs when the loads are applied gradually at a show rate so that the twisting moment increases monotonically from zero to its full value. In this case the internal resisting torque at any stage is in equilibrium with the external applied torque. Most of the torsion tests on concrete members and structural systems reported in the last decades deal with monotonically increasing static torsion. Transient or short-term twisting moments arise due to temporary live loads and environmental effects such as wind and seismic forces. On the other hand long time torsion is produced by dead loads and live loads, which are more or less permanent. The creep under sustained torsion gives rise to higher deformation and reduced stiffness. While short time torsion has been investigated extensively, only few studies deal with long time torsion. Similarly the repetitive torsion in spite of the fact that in common practice the twisting moments are often repetitive or cyclic.[1]

The phenomenon of torsion seldom occurs by itself. It is almost invariably combined with other actions such as flexure and shear. Hence it is combined torsion and bending which is of real practical interest. However, for the sake of insight in to combined torsion it is necessary to understand the phenomenon if pure torsion. This would seem to justify large number of investigations dealing with pure torsion of concrete members.[1]

\subsection{Torsional Strengthening of Beams}

For torsional strengthening, there are many methods such as: section enlargement, stirrup spacing decreasing, external post tensioning method, addition of fibres to concrete etc. While many methods of strengthening structures are available, strengthening structures by adding fibre is one of the advanced techniques. During the past decade, their application in this field has been rising due to the wellknown advantages of FRP composites over other materials. Consequently, a great quantity of research, both experimental and theoretical, has been conducted on the behaviour of FRP-strengthened reinforced concrete (RC) structures. In this regard, the evolving technology of using carbon-bonded fibre-reinforced polymers (CFRP) for strengthening of RC beams has attracted much attention in recent years. 


\subsection{Fibre Reinforced Concrete}

In the plain concrete and similar brittle materials, structural cracks develop even before loading, particularly due to drying shrinkage or other causes of volume change. The width of these cracks seldom exceeds a few microns, but their other two dimensions maybe of higher magnitude.

When loaded, the micro cracks propagate and open up, and owing to the effect of stress concentration, addition a crack form in places of minor defects. The structural cracks proceed slowly or by tiny jumps because various obstacles retard them, changes of direction in by passing the more resistant grains in matrix. The development of such micro cracks is the main cause of inelastic deformation in concrete.

\subsection{Types of Fibres}

Depending upon the parent material used for manufacturing fibres can be broadly classified as;

1. Metallic fibres (e.g. low carbon steel, stainless steel, galvanized iron, aluminum)

2. Mineral fibres (carbon, glass, asbestos etc.)

3. Synthetic fibres (polypropylene, polyethylene, polyester, nylon etc.)

4. Natural fibres (bamboo, coir, jute, sisal, wood, sugarcane bagasse etc.)

\subsection{Glass Fibres}

Glass fibre (or glass fiber) is a material consisting of numerous extremely fine fibres of glass. Glassmakers throughout history have experimented with glass fibres, but mass manufacture of glass fibre was only made possible with the invention of finer machine tooling. In 1893, Edward Drummond Libbey exhibited a dress at the World's Columbian Exposition incorporating glass fibres with the diameter and texture of silk fibres. This was first worn by the popular stage actress of the time Georgia Cayvan. Glass fibres can also occur naturally, as Pele's hair. Glass fibre is formed when thin strands of silica-based or other formulation glass are extruded into many fibres with small diameters suitable for textile processing. The technique of heating and drawing glass into fine fibres has been known for millennia; however, the use of these fibres for textile applications is more recent. Until this time, all glass fibre had been manufactured as staple (that is, clusters of short lengths of fibre).

Table 1 Specification of Glass Fiber

\begin{tabular}{|l|l|l|l|}
\hline Length & Shape & Diameter & Aspect Ratio \\
\hline $12 \mathrm{~mm}$ & Round & $0.01386 \mathrm{~mm}$ & 865.27 \\
\hline
\end{tabular}

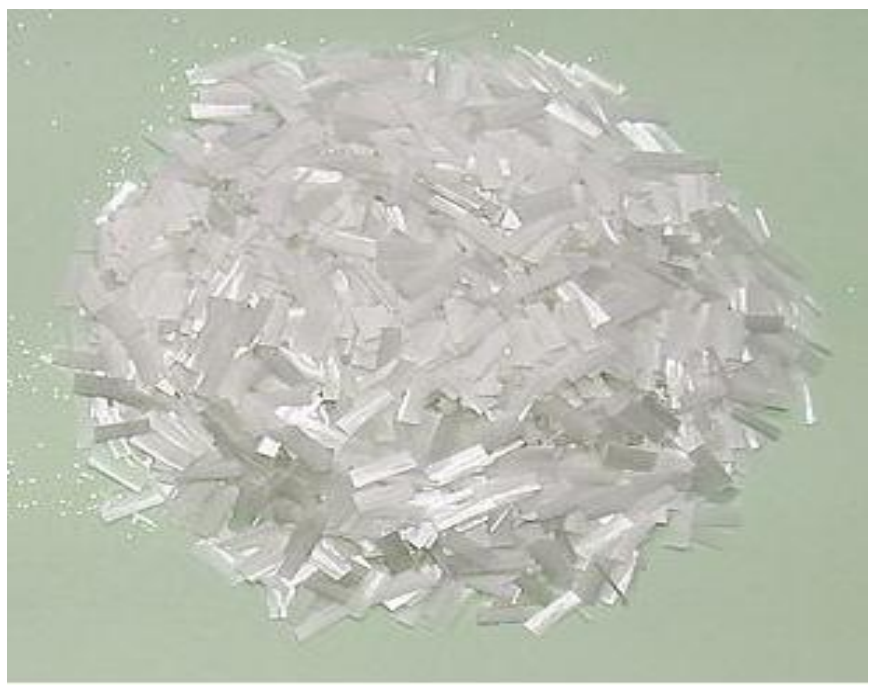

Fig -1: Steel Fibers

\section{EXPERIMENTAL PROGRAM}

The experimental program consists of casting and testing of four RCC beams of size $150 \mathrm{mmx} 150 \mathrm{mmx} 2000 \mathrm{~mm}$. Out of which three of them are glass fibre reinforced and the remaining one is without glass fibres. Within these three beams, one beam is cast with glass(FR 0 ) fibres of $0.5 \%$ by weight(FR 0.5$), 2^{\text {nd }}$ beam of $1.0 \%$ by weight(FR 1$)$ and $3^{\text {rd }}$ one with $1.5 \%$ by weight(FR 1.5). All the beams were tested to study the effects of torsion.

\subsection{Proportioning of Beam Specimen}

The flexural reinforcement consisted of two $8 \mathrm{~mm}$ diameter bars at the bottom and two $8 \mathrm{~mm}$ diameter bars at the top of the beam used as anchor bars. Shear reinforcement was provided in the form of two-legged rectangular stirrups with standard hooks. Stirrups were made of $6 \mathrm{~mm}$ diameter bars. The stirrups were $100 \mathrm{~mm}$ wide and $100 \mathrm{~mm}$ in depth. The center-to-center spacing of the stirrups was $180 \mathrm{~mm}$.[8][9]

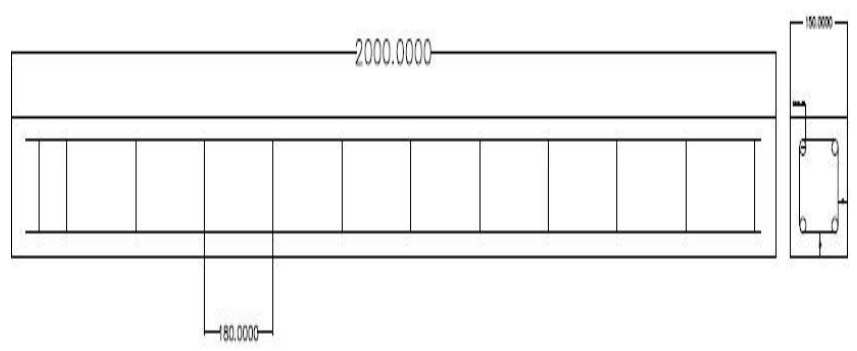

Fig-2 : Details of beam

\subsection{Materials}

The M 20 grade of concrete was used for the casting of RC and RFRC beams. An Ordinary Portland Cement (OPC) of $53 \mathrm{MPa}$ strength, locally available river sand as fine aggregate, crushed stone aggregate with a maximum particle size of $20 \mathrm{~mm}$ as coarse aggregate, Glass fibres and potable water were used in this investigation. The mix proportion obtained from these materials is given in table below; 
Table 2 Mix Proportions for M 20

\begin{tabular}{|l|l|l|l|}
\hline Water & Cement & $\begin{array}{l}\text { Fine } \\
\text { Aggregate }\end{array}$ & $\begin{array}{l}\text { Coarse } \\
\text { Aggregate }\end{array}$ \\
\hline $186 \mathrm{~kg}$ & $454 \mathrm{~kg}$ & $681 \mathrm{~kg}$ & $1362 \mathrm{~kg}$ \\
\hline 0.45 & 1 & 1.5 & 3 \\
\hline
\end{tabular}

$\therefore$ Mix Proportion is $1: 1.5: 3$ [6]

\subsection{Designation of the Beams}

Table 3 Beam Casting Schedule

\begin{tabular}{|l|l|l|}
\hline Beam Type & Designation & $\begin{array}{l}\text { Fiber } \\
(\%)\end{array}$ \\
\hline $\begin{array}{l}\text { Reinforced } \\
\text { Concrete }\end{array}$ & $\begin{array}{l}\text { Fibre Reinforced } \\
\text { FR 0 }\end{array}$ & 0 \\
\hline Glass FRC & FR 0.5 & 0.5 \\
\hline Glass FRC & FR 1 & 1 \\
\hline Glass FRC & FR 1.5 & 1.5 \\
\hline
\end{tabular}

\subsection{Testing of Beams}

All the beams were tested for torsion under UTM of $400 \mathrm{kN}$ in the strength of materials lab of GNI engineering college Hyderabad. The three samples of each type of beam specimen were tested.

All of them are tested in the torsional test arrangement as shown in fig. 3 and 4 . The gradual increase in load at every $0.1 \mathrm{kN}$ were observed for calculation of torsional moment and the deformation observed in the dial gauge with the least count of $0.01 \mathrm{~mm}$ for the calculation of angle of twist of beam.

These increments in readings were taken throughout the test. The load was applied till the ultimate failure of beam. The deflections were taken at one end of the beam, and the torsional moment by angle of twist graph was plotted from the obtained results.

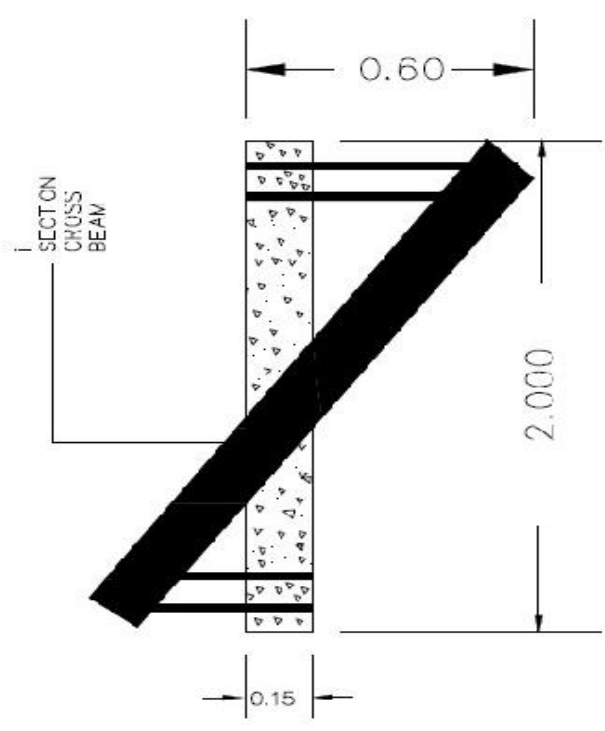

Fig -3: Plan of testing setup

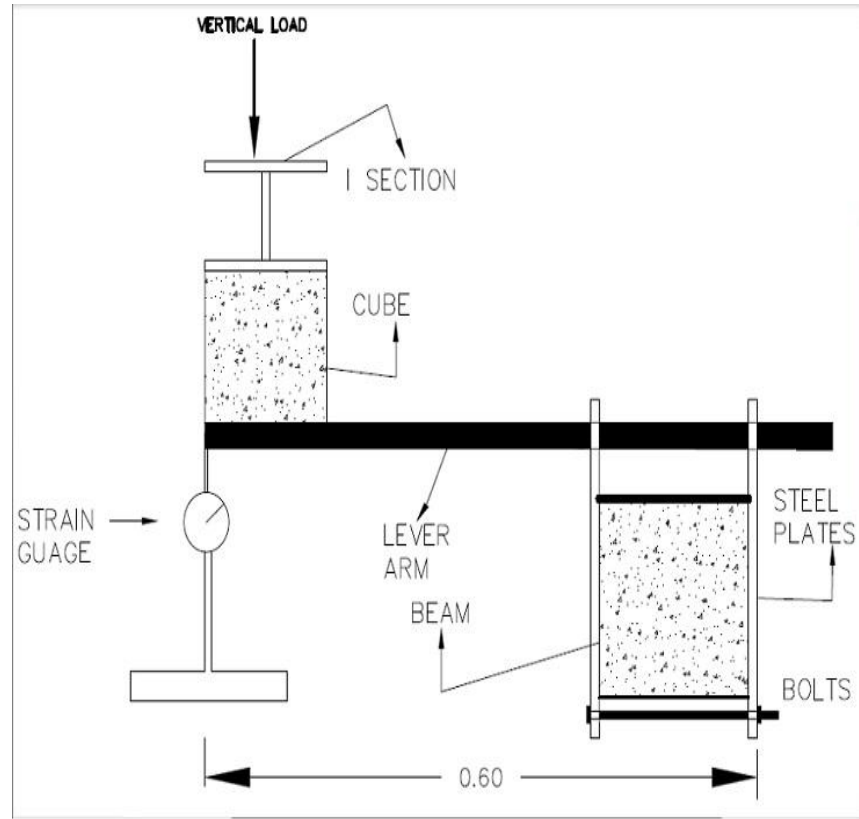

Fig -4: Schematic Test Setup at the End of Specimen

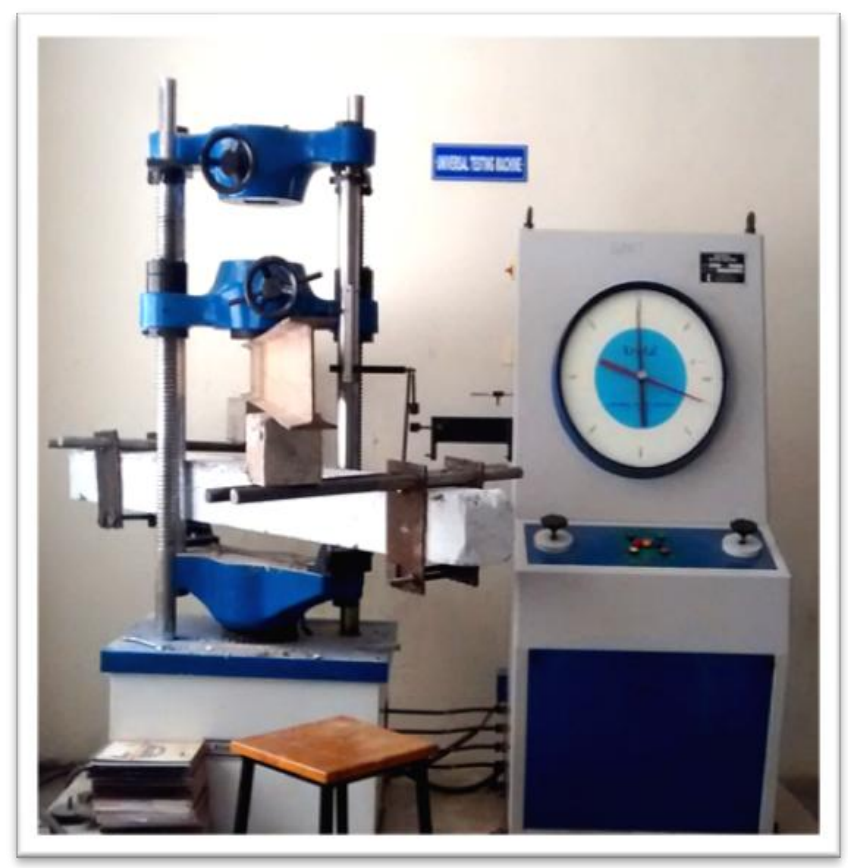

Fig -5: Experimental Setup of the Beam

\section{RESULTS AND DISCUSSION}

The final results at cracking point and ultimate load point obtained after calculations of all the test readings.

Table 4 Test Results of cracking torque

\begin{tabular}{|l|l|l|}
\hline BEAM & $\begin{array}{l}\text { Load } \\
\mathrm{kN}\end{array}$ & $\begin{array}{l}\text { Cracking torque } \\
(\mathrm{kN}-\mathrm{M})\end{array}$ \\
\hline FR 0 & 6 & 4.11 \\
\hline FR 0.5 & 7 & 4.716 \\
\hline FR 1 & 9 & 5.916 \\
\hline FR 1.5 & 11 & 7.116 \\
\hline
\end{tabular}


Table 4 Test Results of ultimate torque

\begin{tabular}{|l|l|l|}
\hline BEAM & $\begin{array}{l}\text { Load } \\
\mathrm{kN}\end{array}$ & $\begin{array}{l}\text { Ultimate torque } \\
(\mathrm{kN}-\mathrm{M})\end{array}$ \\
\hline FR 0 & 9 & 5.916 \\
\hline FR 0.5 & 10 & 6.516 \\
\hline FR 1 & 11 & 7.116 \\
\hline FR 1.5 & 13 & 8.316 \\
\hline
\end{tabular}

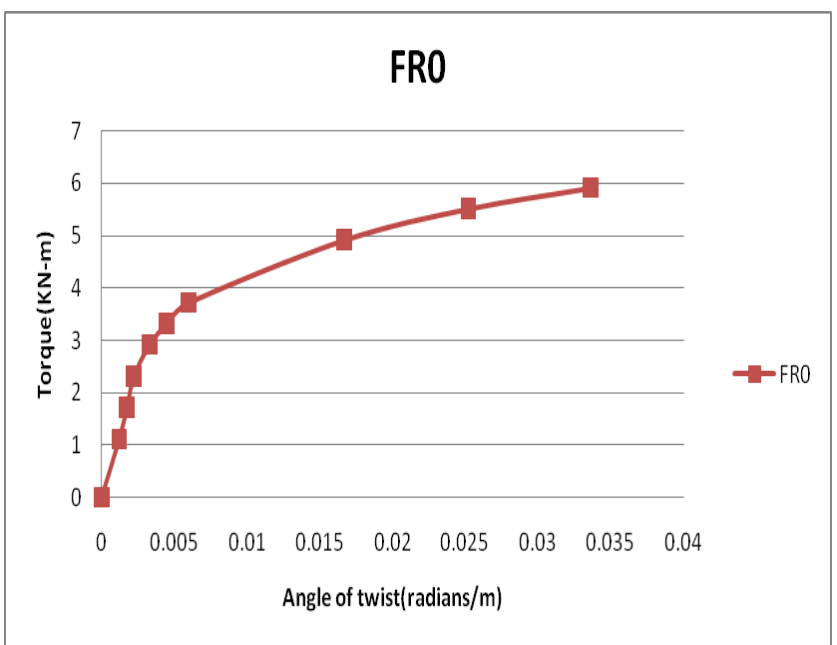

Chart -1: Torque Twist response of FR 0

The FR 0 (control beam) failed completely in torsion at a load of $9 \mathrm{kN}$ and ultimate torque is $5.916 \mathrm{kNm}$. It was observed that cracks were appeared making an angle 400500 with the main beam. The cracks were developed in a spiral pattern all over the main beam which later leads to the failure of the beam in torsional shear.

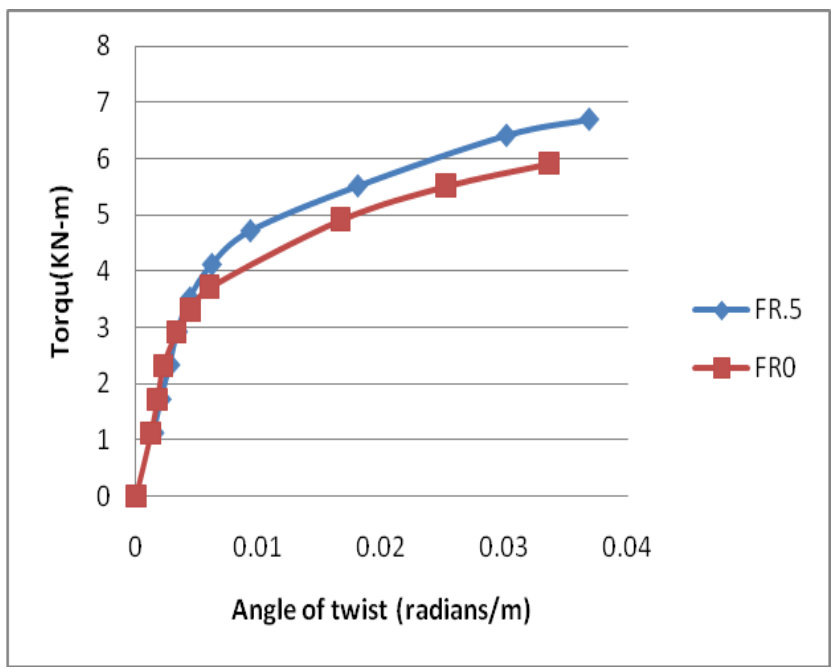

Chart -2: Torque Twist response of FR 0 and FR 0.5

Chart 2: The beam FR 0.5 failed completely in torsion at a load $10 \mathrm{kN}$ and ultimate torque is $6.516 \mathrm{kNm}$. The increase in the strength of beam in ultimate torque was $10.14 \%$ as compared to control beam.

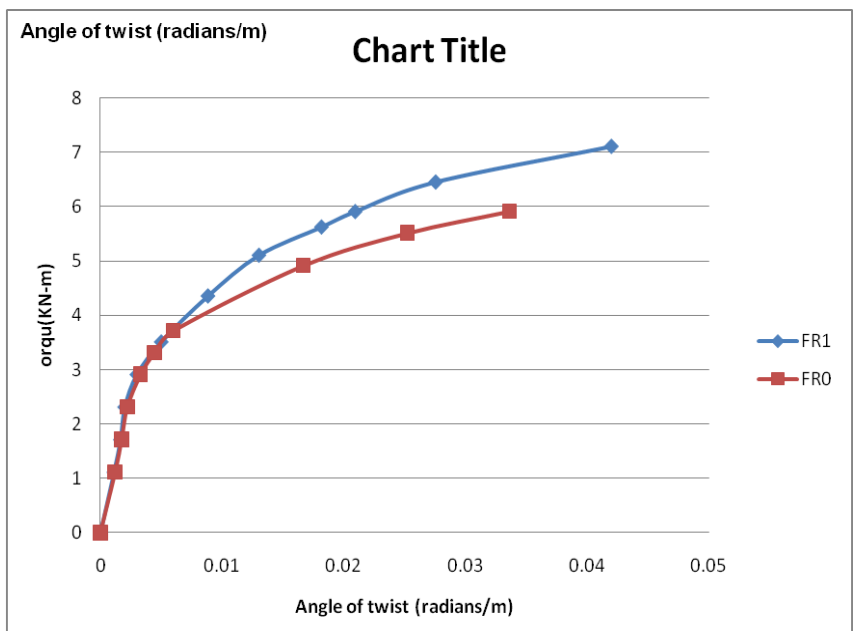

Chart -3: Torque Twist response of FR 0 and FR 1

Chart -3: The beam FR 1 failed completely in torsion at a load $11 \mathrm{kN}$ and ultimate torque is $7.116 \mathrm{kNm}$. The increase in the strength of beam in ultimate torque was $20.28 \%$ as compared to control beam.

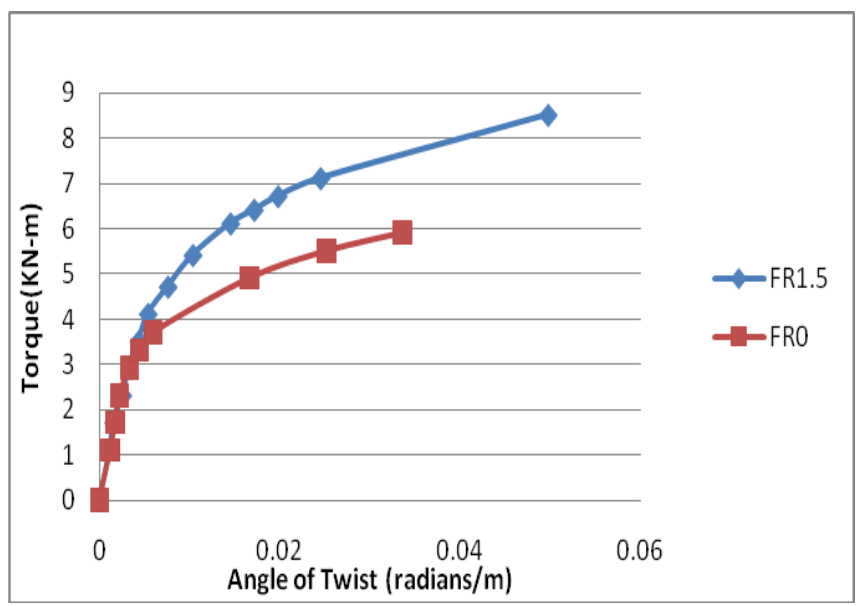

Chart -4: Torque Twist response of FR 0 and FR 1.5

Chart 4: The beam FR 1.5 failed completely in torsion at a load $13 \mathrm{kN}$ and ultimate torque is $8.316 \mathrm{kNm}$. The increase in the strength of beam in ultimate torque was $40.56 \%$ as compared to control beam.

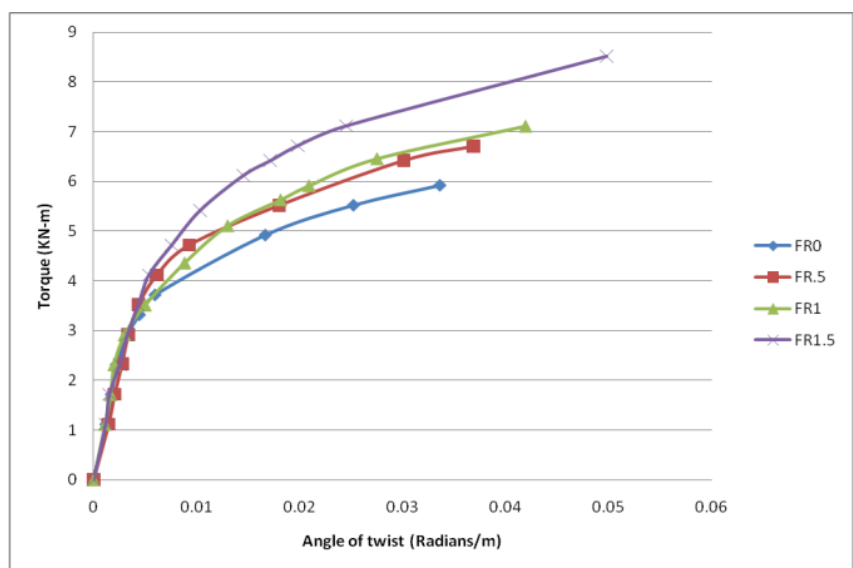

Chart -5: Torque Twist response of FR 0, FR 0.5, FR 1 and FR 1.5 
Chart 5: It is clear that FR 1.5 beam which strengthen with $1.5 \%$ glass fiber fraction experienced largest value of torsional moment(torque) and angle of twist up to the failure of beam.

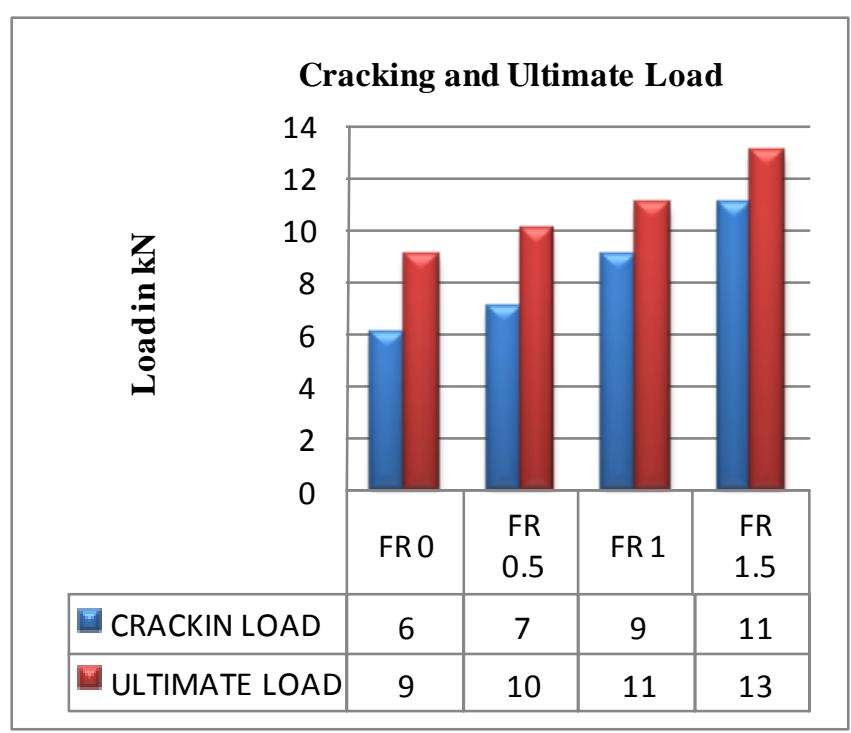

Chart-6 Variation of Cracking load and ultimate load

Above bar diagram shows the cracking and ultimate load taking strength for all glass fibre reinforced beams with respect to FR 0 (control beam), and is observed that FR 1.5 gives maximum cracking and torsional load compared with FR0, FR 0.5 and FR 1.

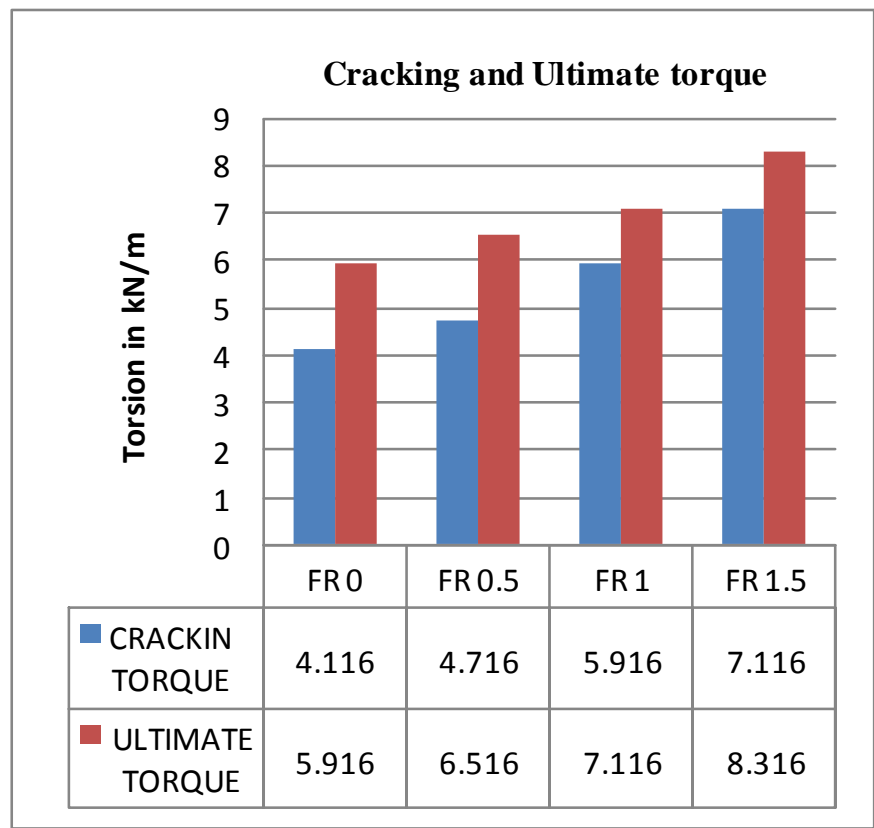

Chart-7 Variation of Cracking Torque and ultimate torque

Above bar diagram shows the cracking and ultimate torsional strength for all glass fibre reinforced beams with respect to FR 0 (control beam), and is observed that FR 1.5 gives maximum cracking and torsional strength compared with FR0, FR 0.5 and FR 1.

\section{CONCLUSION}

From the results obtained following conclusion is drawn;

- Use of fibre has found very beneficial to increase the torsional strength of RC beam subjected to pure torsion.

- The cracking torsional strength of FR 1.5 increased upto $72.8 \%$ which is very significant increase in the strength of concrete compared to conventional RC Beam.

- The ultimate torsional strength of FR 1.5 increased upto $40.56 \%$ which is very significant increase in the strength of concrete compared to conventional RC Beam.

- The fibre reinforced concrete brittleness in decreased and increase in ductility can be observed.

- The fibre reinforcement has also succeeded to increase stiffness of the beam by decrease the angle of twist of strengthen beam compared to conventional RC beam.

- The initial crack pattern has observed at higher loads in the fibre reinforced strengthen beams.

\section{ACKNOWLEDGEMENTS}

I am very thankful to Dr. Veeranna, Director of Guru Nanak Institutional Campus for his guidance and support till end.

\section{REFERENCES}

[1]. Sukontasukkul P. (2004). "Toughness evaluation of steel and polypropylene fibre reinforced concrete beams under bending", Thammasat Int. J. Tech., Vol. 9, Part 3, pp. $35-41$.

[2]. Krishna Rao MV., Dakhshina Murthy NR., Santhosh Kumar V. (2011). "Behaviour of polypropylene fibre reinforced fly ash concrete deep beams in flexure and shear", Asian Journal of Civil Engineering (Building And Housing), Vol. 12, Part 2, pp. 143-154.

[3]. Sable K. S. and Rathi M. K. (2012). "Comparison of normal compacted concrete and self-compacted concrete in shear \& torsion", International Journal of Computer Technology and Electronics Engineering, Vol. 2, Part 4, pp. 74-79.

[4] P. Purushottam, Reinforced Concrete Structureal Elements, Tata-Mc grew-Hill Publishing Company Limited, New Delhi, 1986.

[5]. Perumalsamy N. Balaguru, Surendra P. Shah. Fibre Reinforced Composites. Mc. Grew-Hill International editions, Civil engineering Series pp. 14-187 \& pp. 449-461. [6]. M.S. Shetty, Concrete Technology, S.Chand and Company Limited, New Delhi, 1989.

[7]. C.D. Code, Reinforced Concrete Beams Subjected to sustained Torque, The Structural Engineer, Vol.53, No.5, Mnay 75, pp. 215-220.

[8]. N. Krishnam Raju, Design Of Concrete Mixes, CBS Publishers and Distributors, New Delhi, 1988.

[9]. IS 456:2000, Indian Standard Plain and Reinforced Concrete -code of practice (Fourth Revision). 


\section{BIOGRAPHIES}

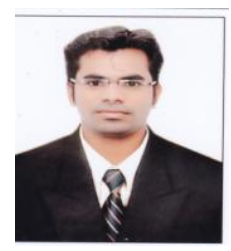

C.Arvind Kumar, Assistant professor, Civil Engineering, Guru Nanak Institution \& Technical Campus, Telengana, India

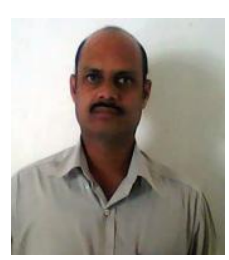

Prof. Madan Mohan, Professor, Civil Engineering, Guru Nanak Institution \& Technical Campus, Telengana, India

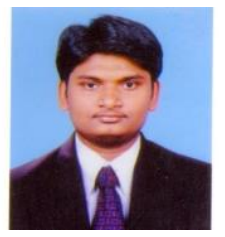

D.V.S.P Rajesh, Assistant Assistant professor, Civil Engineering, Guru Nanak Institution \& Technical Campus, Telengana, India

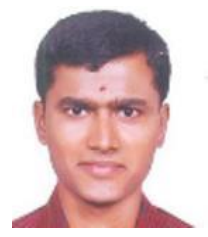

Prathik Kulkarni, Assistant Assistant professor, Civil Engineering, Guru Nanak Institution \& Technical Campus, Telengana, India 